\title{
EFEKTIVITAS BIMBINGAN KELOMPOK DENGAN TEKNIK MODELING DAN TEKNIK GROUP EXERCISES UNTUK MENINGKATKAN KOMPETENSI LITERASI KEAGAMAAN
}

\author{
Nasikhatul Umami ${ }^{1}$, Anwar Sutoyo², Dwi Yuwono Puji Sugiharto ${ }^{3}$ \\ Pascasarjana Universitas Negeri Semarang \\ nasikhatulumami@gmail.com
}

\begin{abstract}
Abstrak
Penelitian ini bertujuan untuk: 1) Menganalisa tingkat kompetensi literasi keagamaan, 2) Menganalisis tingkat keefektifan bimbingan kelompok dengan teknik Modeling dalam meningkatkan kompetensi literasi keagamaan, 3) Menganalisis tingkat keefektifan bimbingan kelompok dengan teknik Group Exercises dalam meningkatkan kompetensi literasi keagamaan, 4) Menganalisis perbedaan keefektifan bimbingan kelompok dengan teknik Modeling dan teknik Group Exercises dalam meningkatkan kompetensi literasi keagamaan. Populasi dalam penelitian ini adalah peserta didik MA AL Manar Kabupaten Semarang yang berjumlah 36 orang, dengan sampel sebanyak 20 orang yang terdiri dari 10 orang kelompok Modeling, dan 10 orang kelompok Group Exercises. Variabel dalam penelitian ini terdiri dari: 1) variabel terikat yaitu Kompetensi Literasi Keagamaan $(\mathrm{Y})$, 2) variabel bebas yaitu: 1) Bimbingan kelompok teknik Modeling $\left(\mathrm{X}_{1}\right)$ dan Bimbingan kelompok teknik Group Exercises $\left(\mathrm{X}_{2}\right)$. Teknik pengumpulan data dengan menggunakan skala psikologi. Teknik analisa data dengan menggunakan Paired Sample t- Test. Hasil penelitian menunjukkan bahwa: 1) Kompetensi literasi keagamaan peserta didik MA Al Manar Kabupaten Semarang meningkat melalui bimbingan kelompok teknik Modeling dan teknik Group Exercises. 2) Bimbingan kelompok dengan teknik Modeling efektif meningkatkan kompetensi literasi keagamaan dengan $\mathrm{p}=0,000<0,05$. 3) Bimbingan kelompok dengan teknik Group Exercises efektif meningkatkan kompetensi literasi keagamaan dengan $\mathrm{p}=0,000<$ 0,05. 4) Terdapat perbedaan bimbingan kelompok dengan teknik Modeling dengan teknik Group Exercises dalam meningkatkan kompetensi literasi keagamaan dengan $\mathrm{p}=0,001<0,05$.
\end{abstract}

Kata Kunci: Teknik Modeling, Group Exercises, Literasi Keagamaan

\section{PENDAHULUAN}

Pendidikan abad ke-21 menuntut kompetensi berliterasi peserta didik, karena berkaitan erat dengan tuntutan keterampilan membaca yang berujung pada kemampuan memahami informasi secara analitis, kritis, dan reflektif. Akan tetapi, pembelajaran di sekolah saat ini belum mampu mewujudkan hal tersebut. Hasil survei yang mengevaluasi kemampuan peserta didik berusia 15 tahun dilakukan oleh Programme for International Student Assessment (PISA) yang mencakup membaca, matematika, dan sains. Berdasarkan laporan PISA yang dirilis, Selasa 3 Desember 2019, khusus dalam kemampuan membaca, Indonesia ada di peringkat 72 dari 77 
negara. Di antara negara-negara Asia Tenggara, Indonesia berada paling bawah bersama Filipina yang mendapat peringkat terakhir dalam membaca dan skor sebelum terakhir di dua bidang lain (Kurnia, 2019: 1).

Hasil penelitian Nurzakiyah (2018) menunjukkan bahwa sekolah menjadi salah satu lembaga pendidikan yang berperan penting dalam menanamkan nilai-nilai moral. Nilai-nilai moral tersebut dapat ditanamkan dan dikuatkan dengan membaca bacaan atau wacana secara kritis atau yang disebut dengan literasi. Literasi, termasuk literasi agama perlu diajarkan kepada peserta didik agar mereka dapat hidup di tengah-tengah masyarakat modern ini. Dalam mempelajari nilai-nilai moral, peserta didik tidak hanya sekedar tahu dan melakukan tanpa tahu maksud dan tujuan nilai tersebut dilakukan. Literasi agama selain menumbuhkan minat membaca juga melatih peserta didik untuk bisa mengkritisi sumber ilmu terkait keagamaan atau nilai-nilai yang dia dapatkan baik dalam bentuk teks (buku), lisan, visual, maupun digital. Melalui pemahaman yang mendalam terhadap sumber-sumber ilmu tersebut dapat memilih berbagai alternatif nilai yang ada dan mengaplikasikannya sebagai wujud aktualisasi diri.

Kompetensi literasi keagamaan menjadi hal yang penting dalam keberhasilan pendidikan moral dengan keluaran menghasilkan peserta didik yang memiliki kompetensi personal dan kompetensi sosial yang memiliki moral luhur dan dinamis sehingga menghasilkan warga negara yang baik. Dalam usaha untuk mewujudkan masyarakat yang bermoral dapat digunakan dengan konsep yang sudah digagas oleh pemerintah dan juga dunia pendidikan. Literasi keagamaan ini tidak hanya kemampuan membaca dan menulis, tetapi di dalamnya juga terdapat literasi meliputi juga kemampuan berbicara, menyimak, dan berpikir sebagai elemen keagamaan di dalamnya.

Penelitian Handaka dan Maulana (2017) menunjukkan bahwa guru bimbingan dan konseling mempunyai peran penting dalam implementasi gerakan literasi nasional. Upaya peningkatan kompetensi literasi keagamaan dapat dilakukan melalui bimbingan kelompok. Bimbingan kelompok sebagai proses membantu peserta didik agar memiliki pemahaman diri dan mengarahkan diri, agar dapat menyesuaikan diri secara maksimal dalam kehidupan di sekolah, rumah, dan masyarakat. Bimbingan kelompok dengan teknik Modeling sebagai suatu cara atau metode dengan menggunakan contoh, teladan atau perilaku seseorang atau beberapa orang teladan berperan sebagai perangsang terhadap pikiran, sikap, perilaku.

Layanan bimbingan kelompok dengan teknik Modeling diharapkan dapat membantu peserta didik dalam meningkatkan kompetensi literasi keagamaan. Sehingga peserta didik mempunyai kemampuan dalam mengembangkan sesuatu yang peroleh dari membaca, menulis dan menjadikan peserta didik menjadi lebih kreatif, produktif, berdaya saing, berkarakter, dan nasionalis serta menumbuhkan budi pekerti yang baik. Selain itu juga dengan kompetensi literasi keagamaan peserta didik dapat menaikkan ketaatan dan kepatuhan terhadap tata tertib dan peraturan sekolah serta menambah pengetahuan.

Selain bimbingan kelompok dengan teknik Modeling, bimbingan kelompok dengan teknik Group Exercises diharapkan dapat meningkatkan kompetensi literasi keagamaan pada peserta didik di MA Al Manar Kabupaten Semarang. Bimbingan kelompok teknik Group Exercises ini memiliki banyak jenis latihan yang dapat diterapkan pada peserta didik berdasarkan tujuannya. Seperti menulis, membaca, gerak, lingkaran, dyad and triad, creative props, arts and crafts, fantasi, bacaan umum, umpan balik, kepercayaan, experiental, dilema moral, keputusan kelompok, dan sentuhan. Dengan banyaknya jenis latihan yang dapat diterapkan dalam bimbingan kelompok group exercises, hal ini di asumsikan dapat meningkatkan interaksi dan dinamika dalam kelompok seperti tujuan dari bimbingan kelompok. Interaksi dan dinamika kelompok dapat ditingkatkan melalui latihan-latihan tersebut, seperti 
dengan bertukarnya pengetahuan dan pengalaman peserta didik terhadap suatu hal, berlatih toleransi dalam mengemukakan pendapat, usaha dalam memahami perasaan dan pesan orang lain, belajar membuat keputusan kelompok. Beberapa hal tersebut tercapai dengan adanya komunikasi, kerjasama, umpan balik dan lain-lain antar anggota kelompok. Peristiwa-peristiwa psikologis antar anggota tersebut dimungkinkan terjadi dalam bimbingan kelompok group exercise. Berdasarkan uraian tersebut, peneliti tertarik untuk meneliti keefektifan bimbingan kelompok dengan teknik Modeling dan teknik Group Exercises terhadap kompetensi literasi keagamaan.

\section{METODE PENELITIAN}

Jenis penelitian ini adalah penelitian eksperimen. Penelitian eksperimen adalah suatu penelitian dengan melakukan kegiatan percobaan (experiment) yang bertujuan untuk mengetahui gejala atau pengaruh yang timbul akibat dari adanya perlakuan tertentu atau eksperimen tersebut (Notoatmodjo, 2010). Penelitian ini menggunakan desain eksperimen semu atau quasy experimental design. Metode quasi experimental adalah metode penelitian eksperimen dengan menggunakan kelompok kontrol, tetapi tidak sepenuhnya mengontrol variabel-variabel luar yang mempengaruhi penelitian (Sugiyono, 2016).

Populasi dalam penelitian ini adalah peserta didik kelas X MA Al Manar Kabupaten Semarang yang terdiri atas 2 kelas dengan jumlah 36 orang peserta didik. Sampel penelitian ini adalah 20 peserta didik dengan 10 orang peserta didik yang diberikan bimbingan kelompok dengan teknik Modeling dan 10 orang peserta didik yang diberikan bimbingan kelompok dengan teknik Group Exercises. Teknik pengambilan sampel dalam penelitian ini adalah sampling purposive.

Teknik pengumpulan data dalam penelitian ini dengan menggunakan skala psikologi. Skala psikologi merupakan suatu alat yang digunakan untuk mengukur atribut psikologis (Azwar, 2010: 3). Skala psikologi disusun dengan mengacu pada skala Likert dengan empat pilihan jawaban. Rentang jawaban tersebut adalah mulai dari Sangat Sesuai (SS), Sesuai (S), Kurang Sesuai (KS), dan Sangat Tidak Sesuai (STS) yang apabila dikonversi dalam bentuk nilai maka nilainya bergerak dari 1 sampai dengan 4.

Teknik analisis data dalam penelitian menggunakan Paired-Sample T Test. Paired-Sample T Test bertujuan untuk mengetahui apakah ada perbedaan rata-rata (mean) antara dua sampel berpasangan. Dalam penelitian ini Paired Sample T Test digunakan untuk mengetahui keefektifan bimbingan kelompok teknik Modeling dan teknik Group Exercises.

\section{HASIL DAN PEMBAHASAN}

Hasil pengukuran pre test kompetensi literasi keagamaan kelompok Modeling menunjukkan bahwa nilai rata-rata (mean) sebesar 55,80, nilai tengah (median) 56,50, nilai yang sering muncul (mode) sebesar 44, standar deviasi sebesar 6,909 nilai minimum sebesar 44 dan nilai maximum sebesar 65. Pre test kompetensi literasi keagamaan kelompok Group Exercises menunjukkan bahwa nilai rata-rata (mean) sebesar 55,50, nilai tengah (median) 57,00, nilai yang sering muncul (mode) sebesar 63, standar deviasi sebesar 6,884, nilai minimum sebesar 44 dan nilai maximum sebesar 63.

Sedangkan hasil pengukuran post test terhadap kompetensi literasi keagamaan pada kelompok Modeling diperoleh hasil nilai rata-rata (mean) sebesar 65,90, nilai tengah (median) 67,50, nilai yang sering muncul (mode) sebesar 68, standar deviasi sebesar 4,909, nilai minimum sebesar 58 dan nilai maximum sebesar 73 . post test terhadap kompetensi literasi keagamaan pada kelompok Group Exercises diperoleh 
hasil nilai rata-rata (mean) sebesar 70,50, nilai tengah (median) 70,50, nilai yang sering muncul (mode) sebesar 69, standar deviasi sebesar 1,581, nilai minimum sebesar 68 dan nilai maximum sebesar 73 .

Hasil analisis data pre - post test pada kelompok Modeling diperoleh hasil mean 10,000 dengan standard deviasi 2,283 dengan thitung $=13,991$ dan $\mathrm{p}=0,000<0,05$, sehingga ada perbedaan yang signifikan antara kompetensi literasi keagamaan kelompok Modeling pada saat belum diberikan layanan bimbingan kelompok dengan teknik Modeling dengan pada setelah diberikan layanan bimbingan kelompok dengan teknik Modeling.

Hasil analisis data pre - post test pada kelompok Group Exercises diperoleh hasil mean 15,300 dengan standard deviasi 5,208 dengan $t_{\text {hitung }}=9,290$ dan $p=0,000<0,05$, sehingga ada perbedaan yang signifikan antara kompetensi literasi keagamaan kelompok Group Exercises pada saat belum diberikan layanan bimbingan kelompok dengan teknik Group Exercises dengan pada setelah diberikan layanan bimbingan kelompok dengan teknik Group Exercises.

Hasil analisis data pre test diperoleh hasil mean 0,300 dengan standard deviasi 1,337 dengan thitung $=0,709$ dan $\mathrm{p}=0,496>0,05$, sehingga tidak ada perbedaan yang signifikan antara kompetensi literasi keagamaan kelompok Modeling dengan kompetensi literasi keagamaan kelompok Group Exercises. Dengan demikian eksperimen dapat dilanjutkan.

Selanjutnya setelah dilakukan eksperimen melalui layanan bimbingan kelompok dengan teknik Modeling dan teknik Group Exercises diberikan post test. Hasil analisis data post test menunjukkan bahwa mean kompetensi literasi keagamaan sebesar 4,900, standar deviasi 3,281 dengan thitung $=4,722$ dengan nilai $\mathrm{p}=0,001<0,05$. Perhitungan statistik tersebut menunjukkan bahwa terdapat perbedaan antara bimbingan kelompok dengan teknik Modeling dan teknik Group Exercises. Hal ini berarti bimbingan kelompok dengan teknik Modeling dan teknik Group Exercises efektif dalam meningkatkan kompetensi literasi keagamaan peserta didik MA Al Manar Kabupaten Semarang.

Terdapat peningkatan kompetensi literasi keagamaan pada peserta didik MA AL Manar Kabupatern Semarang melalui bimbingan kelompok dengan teknik Modeling dan teknik Group Exercises. Romlah (2013: 3) menyatakan bahwa bahwa bimbingan kelompok merupakan salah satu teknik bimbingan yang berusaha membantu individu agar dapat mencapai perkembangannya secara optimal sesuai dengan kemampuan, bakat, minat, serta nilai-nilai yang dianutnya dan dilaksanakan dalam situasi kelompok. Melalui bimbingan kelompok peserta didik berlatih untuk membantu anggota-anggota kelompok untuk mencapai tujuan-tujuan bersama dalam hal ini adalah peningkatan kompetensi literasi keagamaan.

Bimbingan kelompok dengan teknik Modeling efektif diterapkan dalam meningkatkan kompetensi literasi keagamaan pada peserta didik. Bimbingan kelompok dengan teknik Modeling secara simbolik dengan memamerkan perilaku seseorang atau beberapa orang kepada subjek sebagai proses belajar melalui pengamatan, dimana perilaku seseorang atau beberapa orang teladan berperan sebagai perangsang terhadap pikiran, sikap, perilaku pengamat atau tindakan teladan. Menurut Bandura (2011: 340) modeling merupakan bagaimana individu belajar dari mengamati orang lain. Belajar bisa diperoleh memalui pengalaman langsung, bisa pula diperoleh secara tidak langsung dengan mengamati tingkah laku orang lain berikut konsekuensinya.

Peningkatan kompetensi literasi keagamaan sejalan dengan penelitian Skerrett (2014) dengan hasil bahwa kompetensi seorang guru akan membuat peserta didik meningkat literasi keagamaannya dan mampu menghasilkan tulissan-tulisan akademis. Literasi keagamaan merupakan bagian dari implementasi pendidikan karakter di sekolah, dalam hal ini sekolah yang bernuansa agamis. Sebagaimana hasil 
penelitian Tantri dan Dewantara (2017) bahwa minat baca peserta didik dapat ditingkatkan melalui budaya literasi.

Penelitian Handaka dan Maulana (2017) menunjukkan bahwa peranan guru Bimbingan dan Konseling sangat penting dalam implementasi literasi baik itu dalam layanan dasar, layanan responsif, layanan perencanaan individual, dan dukungan sistem. Penerapan bimbingan kelompok dengan teknik Group Exercises sebagai bentuk layanan dasar dalam meningkatkan kompetensi literasi keagamaan peserta didik MA AL Manar Kabupaten Semarang. Jacobs (2012: 222) menjelaskan bahwa melalui latihan (exercises) seseorang diberikan kesempatan untuk belajar melalui pengalaman. Dalam penelitian Nurzakiyah (2018) menunjukkan bahwa literasi agama selain menumbuhkan minat membaca juga melatih peserta didik untuk bisa mengkritisi sumber ilmu terkait keagamaan atau nilai-nilai yang dia dapatkan baik dalam bentuk teks (buku), lisan, visual, maupun digital. Melalui pemahaman yang mendalam terhadap sumber-sumber ilmu tersebut dapat memilih berbagai alternatif nilai yang ada dan mengaplikasikannya sebagai wujud aktualisasi diri.

Kompetensi literasi merupakan kemampuan dalam membaca, menulis, berbicara, mendengar, membayangkan dan melihat. Kemampuan membaca merupakan suatu yang vital bagi peserta didik dan juga literasi sebagai salah satu dari nilai karakter yang dikembangkan di sekolah sesuai dengan Kurikulum 2013. Kompetensi literasi keagamaan ini mulai dari pembiasaan, pengembangan, dan pembelajaran literasi keagamaan.

Dalam kegiatan bimbingan kelompok peserta didik dituntut untuk terlibat aktif di dalamnya dan berlatih bersama-sama dalam meningkatkan kompetensi literasi keagamaan. Peserta didik yang mempunyai hambatan dapat langsung sharing bersama dalam kelompok sehingga dengan kebersamaan dan kesungguhan peserta didik dalam dinamika kelompok maka peserta didik MA Al Manar Kabupaten Semarang semakin bersemangat dalam meningkatkan kompetensi literasi keagamaan pada dirinya.

\section{SIMPULAN}

Dari hasil penelitian dan pembahasan dapat disimpulkan sebagai berikut: Kompetensi literasi keagamaan peserta didik MA Al Manar Kabupaten Semarang meningkat melalui bimbingan kelompok teknik Modeling dan teknik Group Exercises. Bimbingan kelompok dengan teknik Modeling efektif meningkatkan kompetensi literasi keagamaan dengan $\mathrm{p}=0,000<0,05$. Bimbingan kelompok dengan teknik Group Exercises efektif meningkatkan kompetensi literasi keagamaan dengan $\mathrm{p}=0,000<$ 0,05. Terdapat perbedaan bimbingan kelompok dengan teknik Modeling dengan teknik Group Exercises dalam meningkatkan kompetensi literasi keagamaan dengan p = 0,001 $<0,05$.

\section{DAFTAR PUSTAKA}

Bandura. 2011. Social Learning Theory. Prentice-Hall.

Handaka, Irvan Budhi dan Maulana, Cecep. 2017. Peran Guru Bimbingan Dan Konseling dalam Implementasi Gerakan Literasi Nasional. Prosiding Seminar Bimbingan dan Konseling. Vol. 1, No. 1 HIm. 227-237. ISSN: 2579-9908.

Jacobs, Ed E. 2012. Group Counseling: Strategies and Skills, Seventh Edition. USA: Brooks/Cole.

Kurnia, Tommy. 2019. Skor Terbaru PISA: Indonesia Merosot di Bidang Membaca, Sains, dan Matematika. https://www.liputan6.com/global/read/4126480/skorterbaru-pisa-indonesia-merosot-di-bidang-membaca-sains-dan-matematika. 
Nurzakiyah, Cucu. 2018. Literasi Agama Sebagai Alternatif Pendidikan Moral. JPA Vol. 19 No. 2 Juli-Desember 2018 Hlm: 20-29.

Romlah, Tatiek. 2013. Teori dan Praktik Bimbingan Kelompok. Malang: Universitas Negeri Malang.

Skerrett, Allison. 2014. Religious Literacies in a Secular Literacy Classroom. Reading Research Quarterly. Vol. 49 No. 2 Pp: 233-250.

Sugiyono. 2016. Metode Penelitian Kuantitatif Kualitatif dan $R$ \& $D$. Bandung: Alfabeta.

Tantri, Ade Asih Susiari Tantri dan Dewantara, I Putu Mas. 2017. Keefektifan Budaya Literasi Di SD N 3 Banjar Jawa Untuk Meningkatkan Minat Baca. Journal of Education Research and Evaluation. Vol. 1 No. 4 Pp. 204-209. 